\title{
COMPARATIVE ANALYSIS OF PROGRAM DEVELOPMENT PROCESSES IN SIX PROFESSIONS
}

\author{
FLOYD PENNINGTON \\ JOSEPH GREEN
}

\section{ABSTRACT}

This study was designed to examine and describe planning strategies used by persons developing continuing professional education (CPE) programs for six professional fields. From the description of practice in the six professions, a general model portraying the program development process was developed. The research methods used to guide the inquiry were those of grounded theory.

Results indicate planners attend to at least six clusters of activities in their program development processes in a fairly consistent sequence. Results also indicate that there is limited use of knowledge resources available in the literature. Planners did, however, use a wide variety of resources available inside the university and outside the university to plan programs.

Differences in strategies of program development in various professional fields did exist, most often in the order of activities and the emphasis given to specific activities in the program development clusters.

\section{INTRODUCTION}

Inquiry into the processes used by persons who plan learning activities for adults is largely an unexplored area in continuing education research. Research findings on which to base decisions about the superiority of one approach to planning over any other are difficult to find. Guides to planning procedures have been presented based on what is found in the literature, revised personal perceptions, reflection, observation and experience. Brady and Long (1:124) find "Hard data on the comparative 'success,' 'effectiveness,' or long-term results of . . . program planning when specific procedures are followed is rare, if not nonexistent." Jones (5) asserts that the problem is compounded since theoreticians and practitioners generally do not agree on the process by which educational programs for adults should be planned and organized.

FLOYD PENNINGTON is Assistant Director of the Office of Continuing Education, Department of Post Graduate Medicine and Health Professions Education, Medical School, University of Michigan, Ann Arbor, Michigan.

JOSEPH GREEN is Assistant Director of the Interwest Regional Medical Education Center, Veterans Administration Hospital, Salt Lake City, Utah.

This manuscript is based on a paper presented at The Adult Education Research Conference, Toronto, Canada, April, 1976.

Manuscript received March 30, 1976. 
Most current theoretical formulations of program planning in continuing education are borrowed from Tylerian curriculum development approaches used in primary and secondary education. This rational model assumes a planning process that entails a certain sequence of steps, all of which are interrelated and interdependent. Alternative conceptual statements are emerging, describing the planning process as a series of decision points relating to both the explicit design (decisions made only after forethought and consideration of alternatives) and the implicit design (action based on precedent and habit without the consideration of alternatives). The differences in the two models were succinctly described by Walker.

This model is primarily descriptive, whereas the classical model is prescriptive. This model is basically a temporal one: it postulates a beginning (the platform), an end (the design), and a process (deliberation) by means of which the beginning progresses to the end. In contrast, the classical model is a means-end model: it postulates a desired end (the objective), a means for attaining this end (the learning experience), and a process (evaluation) for determining whether the means does indeed bring about the end. (6:58)

The major purpose of the present study was to develop a substantive theory of program planning in continuing professional education which is sponsored by institutions of higher education. Glaser and Strauss (3:22) describe substantive theory as that developed for a substantive, or empirical, area of inquiry. This is in contrast to formal theories developed for a formal or conceptual area of inquiry. A secondary purpose was to study the utility of a form of naturalistic inquiry for developing educational theory, specifically grounded theory. In the process of developing substantive theory, it was hoped that a general model could be devised that described the important activities planners in several professions engaged in as they planned learning activities for practicing professionals.

To be useful to program planners, the generalizations based on the data must enable planners of continuing education activities to understand better the dynamics of the planning process. Many studies in education research attempt to verify existing theory. This study attempted to develop theory, especially propositions that describe program development in continuing professional education. Brunner's review (2) of adult education research found that most studies were limited to descriptions of single programs or to prescriptive analysis of local situations. Few of the findings could be generalized beyond the case or situation studied. Houle (4:11) asserted that "the comparative study of continuing professional education appears to be a most promising field of inquiry, but its rewards will be achieved only by dealing successfully 
with the complexities of method and interpretation. . . "

\section{RESEARCH METHODS}

The seminal idea that guided the research was found in the methodology of grounded theory developed by Glaser and Strauss (3). The techniques used in developing grounded theory provided the tools for the type of inquiry needed in the study.

The researcher goes to the field with a minimum of predetermined assumptions. In studying a number of similar situations, he identifies qualitative similarities and differences and tests the findings in subsequent field work. The researcher concurrently collects, codes, and analyzes the data before deciding what data to collect next and where to find more information in order to develop the theory as it emerges. The criterion for determining when to stop sampling the different groups pertinent to a category is the category's theoretical saturation.

Categories and their properties are interrelated concepts and activities signaled by the data. Both vary in degree of conceptual abstraction. For example, in this study, six categories were identified; the first was labeled "Originating the Idea." The concepts and activities included in this category were the variety of program idea sources, the role perspectives represented by these sources, and the degrees of sophisticated actions required to make decisions about the information which would lead to other program development activities. The categories are discussed in detail below.

Saturation means that no new information is being found that enables the researcher to further develop a category. The continuous process of theoretical sampling will provide different views or vantage points from which to understand a category and to develop its properties. These views are called slices of data. The final stage in theory building involves collecting the coded data on each category, crosschecking for validity and strength of relationship, and developing hypotheses to be empirically tested. In this study, the theory was portrayed as a planning process model which is discussed below.

\section{DATA COLLECTION}

The subjects selected for the study were planners of the continuing education programs sponsored by the eleven institutions participating in the Committee on Institutional Cooperation (CIC). The University of Chicago and all the Big Ten universities are participants in CIC.

The program planning processes used by planners in the development of continuing education activities in six fields were studied. The six fields were business administration, educational administration, law, teaching, social work and medicine.

Subjects for the interviews were selected from five of the eleven 
institutions. Contact was made with the deans or directors of continuing education at the five institutions to explain the study and help arrange interviews with one or two people who had personally been involved in planning continuing professional education programs in each of the six professional fields.

Informal contact with continuing education administrators from each campus to be visited was made at a national convention which they attended. A brief description of the study was given and names of individuals who might be interviewed were solicited. Each person identified by the campus administrator was contacted by the researcher or by a liaison agent on his campus to schedule time for an interview.

The first personal contact at each campus was with the person(s) who helped arrange the visit and schedule the interviews for the team of two researchers. An abbreviated overview of the study was presented. The research team was given background information about the campus administrative structure for continuing education and a briefing on who would be interviewed. One to three persons in each profession at each school were interviewed. Thirty-seven interviews were conducted. Since some interviews were conducted with more than one person, a total of fifty-two persons were interviewed.

The interview guide was developed and tested with University of Illinois Continuing Education and Public Service staff and selected faculty members. The guide was field tested at one institution prior to use at the other universities.

The interview was responsive to the differences in programs; however, in most cases all topics in the guide were covered in each interview. The main concern was not to impose any structure on respondents' descriptions of the program development process. The outline of each interview was generally: 1) an explanation of the project to the respondent, 2) a request for a brief description of one program and the planning process used in developing the program, 3) the interviewer repeating what he understood the planning process to be, 4) clarification of the planning process, and 5) probing questions concerning specific aspects of the planning process.

Interviews were conducted in the respondents' offices. Each interview lasted approximately one hour and involved one interviewer and one or more respondents. The interviewer noted responses on the interview guide. Following each interview, time was allocated for the researcher to write-up more extensive notes. At the end of each day, the researchers exchanged notes and discussed the emerging results. Some field notes were read by colleagues when the researchers returned to their home campus. 


\section{RESULTS}

Categories that emerged during the interviews were tested, expanded upon, or dropped in subsequent field work. A flow chart was prepared that portrayed the program planning processes reported by each individual. Data were then combined and flow charts were developed to depict relationships among the various categories for each of the six professional fields. These six program planning process models were then merged into one General Model. The General Model was compared and contrasted with individual models and with the model prepared for each group. Comparisons were made using descriptive data, similarities and differences in planning processes and issues that affected planning within and across groups. The General Model was revised as a result of this careful analysis.

Results supported the idea that the planning process comprised a series of tasks and decisions that seemed to cluster around six groups of activities. The term cluster is used to describe a single group of activities. There was some overlap between those clusters that occurred in sequence, as well as between all clusters and the activities described as "Originating the Idea."

The specific activities reported within each of the clusters represent a composite of the data from the interviews. Specific quotes are not used in favor of descriptions of the categories that contributed to the development of the theoretical model which is portrayed in Figure 1.

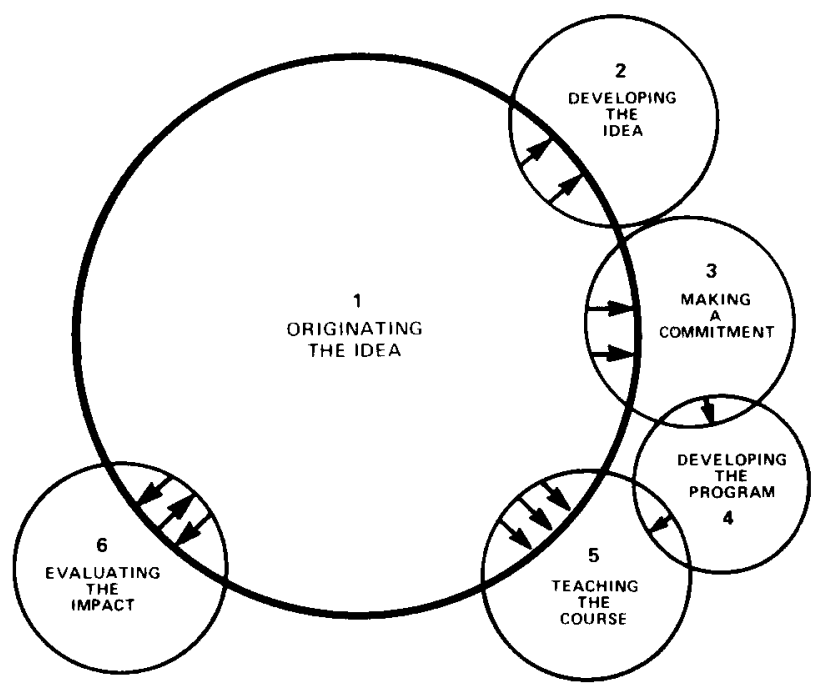

Fig. 1. General Planning Model 
Cluster one is labeled "Originating the Idea." The idea or request for the program came to or from a person on the campus. During the interviews, several origins were suggested:

1. A formal needs assessment

2. Requests from a client or client group

3. The availability of project monies

4. Legislative mandate

5. Suggestions from campus faculty and staff

Ideas originating from the outside requests were received by some person on campus, either a faculty member or a continuing education staff member. After the idea was received, clarification of the topic began. This led to the second cluster.

Cluster two is labeled "Developing the Idea." The activities that occurred in this cluster were those designed to test and refine the idea before a commitment to proceed with a program was made. Several activities were mentioned in the interviews:

1. The idea was tested informally with other practicing professionals to explore the extent of interest in the field.

2. The idea was tested with campus peers to help identify resources and begin to make the idea more specific and manageable.

3. A review of literature was conducted as a source of current ideas related to the program request.

4. Some assessment of institutional interest and delivery capabilities was made to determine if this program was one the institution could or cared to plan.

5. Planners were enlisted to shape the possible response to the request.

6. Some market analysis was done to see if the program would pay for itself.

7. A structured needs assessment focusing on the extent of interest in the idea was conducted.

Not every planner engaged in all of these activities before deciding to conduct the program. Some planners engaged in only one of the activities. In virtually every case, some activity or series of activities did occur to set boundaries around the idea, gather resource support, and get some preliminary commitments to the idea and the possible program.

Cluster three is labeled "Making a Commitment." After the preliminary work was done that led to the decision to go through with the program and some person or persons were identified as planners, a number of activities occurred to formalize the effort. 
1. An instructor was selected and in some instances provided with orientation concerning teaching adults.

2. A decision was made concerning the use of campus faculty members or outside experts.

3. A decision was made about using an existing campus course or some revision of an existing campus course, or developing a new learning activity for the program.

4. Some consideration was given to why the professionals wanted to attend the activity and what the probable characteristics of the target audience would be.

5. The logistics of recruitment, publicity and arrangements for facilities were started.

Not all of these activities would be completed before "Developing the Program" began. In this fourth cluster, which included the following activities, instructional design was the main concern.

1. Objectives were determined.

2. Objectives were stated.

3. Subject matter was developed.

4. A review of literature might occur.

5. Materials were designed or accumulated.

6. Instructional methods were selected.

Some of the recruitment and publicity efforts were started. A better idea of needed facilities and equipment was obtained. Recruitment was completed and the activity was ready to happen.

Cluster five is labeled "Teaching the Course." This was the result of all planning and preparation. In this cluster, the learning activity occurred. It usually occurred as planned, but some flexibility was maintained that permitted changes in focus and methods in response to learner needs. Some evaluation of the activity occurred during the program or immediately following the activity.

Cluster six is labeled "Evaluating the Impact." The activities here were usually the result of previous planning.

1. Determination of methods for judging the success of the program.

2. Determination of what to evaluate.

3. Development of evaluation instruments.

4. Determination of who would use the evaluation.

5. Administration of the evaluation.

6. Utilization of the evaluation results.

The General Model (Figure 1) indicates the nature of the interrelationships among the six activity clusters. Clusters 2, 3, 5, and 6 all interact with Cluster 1, "Originating the Idea." The arrows between 
"Evaluating the Impact" and "Originating the Idea" show some evaluation data being fed into the origination of the idea. Most program planning activities took place in Clusters 2 and 4 . (The size of the circles does not indicate the relative number of activities within the clusters.) The sequential order of the clusters corresponds with the numbers (1-6).

The lists of activities under each cluster are not exhaustive of all possible planning activities. They were the ones most often mentioned in the interviews. Every planner attended to each cluster in some way, although not always in a linear fashion. Nevertheless, at some time during the planning process some work related to each cluster occurred.

\section{DISCUSSION}

It struck the researchers that program development was a form of administrative decision making. Some stimulus from inside or outside of the organization received the attention of a planning agent. The planning agent responded to the stimulus, usually a request or idea for a continuing education activity, in a preliminary fashion to check its strength. If the strength of the stimulus was sufficient, resources were gathered to respond. The response took the form of a number of critical decisions and a consideration of alternative activities which would lead to the execution of those decisions that in the end shaped the educational activity.

Ideally, all clusters of activities focused on facilitating the teaching learning transaction. On several occasions, persons interviewed indicated that the way they planned was "by the seat of the pants." This study proposes a structure for that intuitive response. How well an intuitive approach to planning can and does focus on the product must be tested in future research.

This study brought to light some very important discrepancies between program planning models found within the literature and actual practice in diverse fields of continuing professional education. Planning, as described by those planners involved with this study, was superficial at best. In comparing existing planning procedures with ideal models described in the literature, four major discrepancies emerged:

Analysis of Client Needs: Although there was indication of some of these types of activities preceding programs, the overall picture portrayed by the data was that little comprehensive needs assessment was being conducted. Lack of time, resources, and expertise were the major reasons mentioned when planners were asked why this situation existed. Most planners gave lip service to the importance of needs assessment, but very few followed through. In the authors' opinion, the additional time and money spent in basing educational endeavors on documented educational needs represents a long-term savings and investment. Al- 
though programs may be well planned and evaluated in depth, without baseline data indicating a need for such an effort the program may be providing learning opportunities for needs the target professionals never had.

Systematic Determination of Objectives: If programs were based on the documented needs of a target audience, systematically determining objectives becomes the next critical activity. An end result of needs assessment would be a listing and prioritizing of learning objectives. Other sources of program objectives mentioned in the literature and in isolated instances in this study include previous programs, literature reviews, and opinions of experts. In most cases, when objectives were determined "systematically," only one of the above sources was utilized; however, the ideal in the authors' judgment is to use as many sources as possible. This comprehensive approach to developing objectives rarely occurred. A second aspect of developing ideal objectives is to specify the nature of the learning tasks-cognitive, behavioral or affective. Determining objectives is essential if we are to make judgements about how well the program is meeting the needs of practitioners. In many situations, this is not being done because planners lack the expertise, or because barriers in their work settings do not permit them to exercise their expertise.

Designing Instruction: Carefully chosen educational formats and methods have a great potential for improving the responsiveness and impact of continuing professional education programs. Lectures and group discussions are not always the most appropriate methods. A body of literature and research exists on the subject of selecting methods and media based on learner characteristics, desired learning outcomes, time, money, and other available resources. No indication of planning decisions based on these criteria was found in the present study. Lack of time or expertise was given as a reason for why these activities did not occur.

Comprehensive Evaluation: This term does not describe evaluation practices in continuing professional education programs as observed in this study. The term signifies attempts at judging the real-world impact of educational efforts. Evaluation methods include within-course evaluation, pre-post testing, post workshop questionnaires, pre-workshop procedural analyses and post-workshop field follow-up, phone interviews, or questionnaires. Combinations of these procedures provide data that can help in the accurate assessment of impact. What occurred most often in practice was the use of one or a few of these methods. Evaluation can be very time consuming, but should be viewed as a long-term investment. Continuing professional education planners must become 
aware of various cost-effective evaluation methods and their value.

What appeared to be occurring as those interviewed described their planning strategies was a blending of what Walker (6:58) labelled a "classical" model and a "temporal" model. Planners use the language of the classical model to label their planning actions. However, as they describe their planning actions it becomes clear that personal values, environmental constraints, available resource alternatives, and other factors impinge on the program development process. These actions have received little attention in the literature, but probably represent a major set of critical factors for program development in continuing professional education.

\section{SUGGESTIONS FOR FURTHER INVESTIGATION}

The programs and planning processes reported by respondents in this study were ones the planners judged as successful. Investigations into the planning processes of unsuccessful programs might prove to be interesting and helpful. Factors in the planning process of successful programs could then be compared to the planning processes of programs judged unsuccessful. A preliminary task will be to gain agreement on criteria of successful programs.

Research needs to be conducted that will provide specific information about what clusters of planning activities are most crucial to any program development effort. More detail needs to be provided concerning which activities and decisions consistently occur and can be included in the clusters identified in this study. What are the properties of these categories? Are some clusters more important than others? Are there specific activities within the clusters which cannot be neglected? How important is the sequence of clusters to an efficient planning model?

A more precise investigation should be made of critical relationships that exist between the clusters. Is the planner the person who creates the relationships based on his own values, insights, and environmental constraints? How useful is the notion that the planner is a linkage agent bringing together resources through the program development process? Ideally, the purpose of research in program development will not only be to improve planning efficiency and effectiveness but to focus on improving the quality of learning activities for the professional's continuing education. Effective planning decisions should focus constantly on the ultimate teaching-learning encounter.

\section{CONCLUSION}

Planning continuing professional education programs is a highly individualistic activity as the planner moves through the development 
process. There are clusters of activities that planners attend to somewhat in sequence. The decisions planners make to keep the program development process moving involve consideration of the environment in which they are operating, internal and external constraints and resources, and the possible outcome of any decision. The more effectively the planner deals with these issues in completing tasks within each cluster, the more effective and efficient the program development process will be.

Planners who understand the essential activities that must be attended to in planning programs in their situations can strengthen the operational aspects of those decisions. Their insights need to be shared with peers in the field and will become data for expanding and refining our collective grounded theory of program development.

\section{REFERENCES}

1. Brady, Henry G., and Long, Huey B. "Differences in Perceptions of Program Planning Procedures." Adult Education, XXII (1972), 122-35.

2. Brunner, Edmund de S. et al. An Overview of Adult Education Research. Chicago: Adult Education Association, 1959.

3. Glaser, Barney G., and Strauss, Anselm L. The Discovery of Grounded Theory. Chicago: Aldine Publishing Company, 1967.

4. Houle, Cyril. "The Comparative Study of Continuing Professional Education." Convergence, III (1970), 3-12.

5. Jones, Charles. "Planning Educational Programs for Adults-Theory and Practice." Adult Leadership, (September, 1973), $89 \mathrm{ff}$.

6. Walker, Decker. "A Naturalistic Model of Curriculum Development." The School Review, LXXX (1971), 51-65. 